\title{
Uji Pasar terhadap Buah Pimento di Bali (Studi Kasus di Wilayah Badung dan Denpasar)
}

\author{
WAHYU DWI. A ${ }^{1)}$, KETUT BUDI. ${ }^{2)}$, I.W.BUDIASA. ${ }^{2)}$ \\ Program Studi Magister Agribisnis, Program Pascasarjana, Universitas Udayana, \\ E-mail:wahyuaremania@yahoo.com \\ 1) Program Studi Magister Agribisnis, Program Pascasarjana, Universitas Udayana \\ 2) Program Studi Magister Agribisnis, Program Pascasarjana, Universitas Udayana
}

\section{ABSTRACT \\ Market Test on Pimento Fruits at Bali (Case Study in Badung and Denpasar Region)}

Pimento is one of potencial agriculture comodity will be developed. Pimento is one of a plant in category of chilli genus and its category of sweet chilli. Present Pimento are many consumed by at the high class consumer and foreign, and its selling just only at certaint supermarket. Paprika is easier got and many sell at market. This study aims to find out whether the pimento fruits able to compete with Paprika which has been exist in the market, to know whether Pimento fruits able to accept or not by the public in the market, to know what indicators become consumer considerations to buy and to consume Pimento. This study was conducted in Badung region especially Kuta area and conducted at supermarket that sell Pimento. Sample of consumer are 31 persons who was taken. Data analysis in was conducted by descriptive analysis and Mann Whitney test.

The result shows Pimento fruits is not yet able to compete with Paprika fruits. Pimento price is Rp144.935,48/ kg, four times more expensive than Paprika that only Rp $35.854,83 / \mathrm{kg}$. Mean of Paprika sales was $2,29 \mathrm{~kg} /$ person/month than Pimento was only 0,63 $\mathrm{kg} / \mathrm{person} / \mathrm{month}$ and mean of frequency the Paprika purchased by people 9,74 times/month more than Pimento that was only 3,19 times/month. Present Pimento acceptance is limited at middle class and foriegn and just only sell at certain place. Indicator become consumer consideration to buy Pimento as follows forms, aroma, colour, taste, and benefit as main course.

We recommended that Pimento fruits need for wider production and promotion, marketing place, more marketed segmentation and cheaper price.

Keywords: market test, Pimento, Paprika

\section{Pendahuluan}

\section{Latar Belakang}

Krisis ekonomi yang berkepanjangan telah membuat keterpurukan kondisi perekonomian bangsa Indonesia yang berakibat terjadinya inflasi sehingga kemampuan daya beli masyarakat menurun, berkurangnya sumber pendapatan, meningkatnya pengangguran. Kebijakan pembangunan ekonomi Indonesia yang terlalu berpihak kepada sistem konglomerasi industri (substitusi impor) membuat Negara Indonesia menghadapi kesulitan besar di tengah-tengah isu yang mengatakan bahwa sistem perekonomian Indonesia ini kuat 
dalam menghadapi krisis. Runtuhnya sektor industri moderen sebagai akibat krisis ekonomi menyentuh pemikiran masyarakat untuk mereformasi paradigma lama ke arah paradigma baru dengan menerapkan sistem ekonomi kerakyatan yaitu sistem ekonomi yang berbasis pada kekuatan ekonomi rakyat yang merupakan usaha kecil dan menengah.

Di tengah krisis ekonomi tersebut kemudian muncul seruan agar pembangunan Indonesia kembali kepada sektor pertanian yang berarti menggalakkan lagi swasembada produk pertanian lokal dengan sedikit mengurangi ketergantungan terhadap produk pertanian impor yang semakin hari semakin membanjiri pasaran domestik.

Supartha (2005) menyatakan, kebijakan makro politik ekonomi pada masa lalu mewarnai semua kerangka pemikiran dan operasionalisasi dalm bidang pertanian, misalnya kebijakan ekspor impor, perdagangan monopolistis, lingkungan sosial budaya masyarakat, sikap mental seluruh masyarakat Indonesia, pendidikan petani yang sangat rendah, pengetahuan dan ketrampilan petani, kemampuan dalam mengakses teknologi, informasi, permodalan dan lain-lain.

Menurut Antara (2009), potensi dan prospek pengembangan pertanian di Indonesia sangat bagus. Beberapa potensi yang sangat mendukung untuk pengembangan pertanian di Indonesia antara lain tersedianya lahan pertanian yang cukup luas, banyaknya komoditaskomoditas pertanian, perkebunan, dan juga perikanan yang menjadi andalan ekspor Indonesia, serta tersedianya SDM yang cukup melimpah. Selain itu tingginya permintaan pasar domestik dan internasional akan komoditi pertanian Indonesia juga merupakan prospek yang cukup bagus dalam pengembangan agribisnis di Indonesia.

Salah satu komoditi pertanian yang sangat potensial untuk dikembangkan adalah buah Pimento. Pimento adalah salah satu jenis tanaman baru yang masih termasuk famili tanaman Cabai dan masuk dalam golongan Cabai Manis atau sweet pepper. Tanaman ini berasal dari luar Indonesia dan baru masuk ke Indonesia sekitar pertengahan 2010. Tanaman ini pertama kali dibudidayakan di daerah Cangar, Batu, Malang. Pimento selama ini lebih banyak dikonsumsi oleh masyarakat kalangan atas dan warga negara asing, bahkan penjualannya pun hanya dilakukan di supermarket-supermarket tertentu yang sebagian besar pengunjungnya adalah kalangan lapisan atas baik itu dari warga Indonesia sendiri maupun dari warga negara asing.

Pimento sebenarnya cukup potensial untuk dikembangkan di Indonesia terutama di daerah pegunungan yang beriklim sejuk. Namun informasi yang terbatas mengenai Pimento, membuat pengembangan tanaman ini sangat lambat dan hanya sedikit sekali kalangan yang mengetahui tentang jenis tanaman yang satu ini. Menurut Anas (dalam Riana, 2015), beberapa kalangan juga ada yang menjadikan tanaman Pimento sebagai tanaman hias. Hal ini dikarenakan budidaya Pimento yang masih jarang serta harga benih yang cukup mahal karena harus mengimpor dari luar.

Sebagai produk baru yang sedang berkembang, tentunya Pimento membutuhkan promosi secara lebih luas agar dapat diterima di seluruh kalangan masyarakat, sehingga masyarakat luas dapat lebih mengenal apa dan bagaimana buah Pimento itu sendiri. Berbeda dengan Pimento, buah Paprika yang juga masih termasuk dalam famili tanaman Cabai dan juga termasuk golongan Cabai Manis atau sweet pepper telah terlebih dahulu dikenal oleh masyarakat. Bahkan dibandingkan dengan Pimento, Paprika lebih mudah didapatkan dan banyak dijual di pasaran. Dari segi produksi, Paprika jauh lebih banyak dari pada Pimento. Pada tahun 2013, berdasarkan data dari BPS (2014) produksi Paprika nasional mencapai 8.615 ton dan produksi di Bali sendiri mencapai 309 ton. Sedangkan pada tahun 2014, berdasarkan data dari BPS (2015) produksi Paprika nasional mencapai 7.028 ton dan produksi di Bali sendiri mencapai 361 ton. Khusus Pimento sendiri, berdasarkan data produksi PT Anugerah Mirah Sentosa yang merupakan distributor dari Pimento, produksi di tingkat nasional (meliputi Bali dan Malang) pada tahun 2013 mencapai 430 kg sedangkan 
produksi di Bali sendiri mencapai $329 \mathrm{~kg}$. Pada tahun 2014 produksi Pimento tingkat nasional (meliputi Bali dan Malang) mencapai $580 \mathrm{~kg}$ sedangkan produksi di Bali sendiri mencapai $100 \mathrm{~kg}$.

Walaupun Paprika telah terlebih dahulu dikenal oleh masyarakat dari pada Pimento, namun diperlukan juga semacam uji persepsi konsumen terhadap kedua buah ini. Apakah masyarakat lebih menyukai dan menggemari Pimento dari pada Paprika ataukah sebaliknya masyarakat lebih menyukai Paprika dari pada Pimento. Dengan adanya uji pasar terhadap produk buah Pimento ini diharapkan dapat mengetahui bagaimana tanggapan dan persepsi konsumen terhadap buah Pimento dibandingkan dengan buah Paprika serta untuk mengetahui apakah buah Pimento ini dapat bersaing di pasaran dengan buah Paprika atau tidak.

\section{Perumusan Masalah}

Berdasarkan uraian pada latar belakang di atas, maka dapat dirumuskan permasalahan sebagai berikut:

1. Apakah buah Pimento ini dapat bersaing atau tidak dengan produk buah Paprika yang sudah terlebih dahulu ada di pasaran?

2. Apakah buah Pimento ini dapat diterima atau tidak oleh masyarakat?

3. Parameter apa sajakah yang menjadi pertimbangan konsumen dalam membeli dan mengkonsumsi produk buah Pimento?

\section{Tujuan Penelitian}

Mengacu pada uraian latar belakang dan perumusan masalah yang telah ditentukan maka tujuan yang hendak dicapai pada penelitian ini sebagai berikut:

1. Untuk mengetahui apakah buah Pimento ini dapat bersaing dengan buah Paprika yang sudah terlebih dahulu ada di pasaran

2. Untuk mengetahui apakah produk buah Pimento ini dapat diterima atau tidak oleh masyarakat

3. Untuk mengetahui parameter apa sajakah yang menjadi pertimbangan konsumen dalam membeli dan mengkonsumsi produk buah Pimento

\section{Metode Penelitian}

Penelitian ini dilakukan di wilayah Badung khususnya daerah Kuta, tepatnya dilakukan di supermarket-supermarket yang menjual produk buah Pimento, yaitu di supermarket Freshtiv dan Canggu Deli. Penelitian dilakukan di supermarket tersebut dengan beberapa pertimbangan, antara lain produk buah Pimento banyak dijual di supermarketsupermarket tersebut yang banyak dikunjungi oleh masyarakat menengah atas dan para ekspatriat. Penelitian ini dilaksanakan selama dua bulan yaitu mulai bulan Oktober sampai Desember 2015.

Sumber data yang dikumpulkan adalah data primer dan sekunder. Data primer adalah data yang diperoleh langsung dari sumber yaitu wawancara dan diskusi langsung dengan para responden. Sedangkan data sekunder adalah data yang dikumpulkan dari kantor atau instansi yang ada kaitannya dengan penelitian ini.

Data primer dan sekunder terbagi menjadi dua jenis yaitu data kuantitatif dan data kualitatif. Data primer kuantitatif adalah data primer yang diperoleh langsung dari sumber dan berupa angka-angka yaitu jumlah responden, umur responden, pendapatan responden, jumlah buah yang dibeli, harga buah. Sedangkan data primer kualitatif adalah data primer yang diperoleh langsung dari sumber dan tidak berupa angka-angka yaitu karakteristik buah, manfaat buah, ketersediaan buah, dan frekuensi pembelian buah. 
Data sekunder kuantitatif adalah data sekunder yang dikumpulkan dari kantor atau instansi yang ada kaitannya dengan penelitian ini dan berupa angka-angka yaitu data produksi Pimento dan Paprika. Sedangkan, data sekunder kualitatif adalah data sekunder yang dikumpulkan dari kantor atau instansi yang ada kaitannya dengan penelitian ini dan tidak berupa angka-angka yaitu laporan penelitian seperti skripsi, jurnal, dan tesis, buku-buku literatur.

Metode pengumpulan data yang digunakan dalam penelitian ini adalah melalui survei dengan melakukan wawancara mendalam terhadap konsumen menggunakan kuisioner yang telah dipersiapkan sebelumnya dan studi kepustakaan dengan melakukan pengumpulan data melalui buku-buku, laporan-laporan penelitian yang berhubungan dengan penelitian ini.

Responden penelitian dipilih berdasarkan tujuan penelitian dalam hal ini konsumen yang membeli buah Pimento. Penarikan sampel menggunakan teknik Accidental Sampling yang merupakan penarikan sampel secara kebetulan, yaitu populasi sasaran yang membeli Pimento dan secara kebetulan bertemu dengan peneliti saat melakukan survei.

Pengambilan sampel dilakukan di supermarket-supermarket yang menjual produk buah Pimento dengan jumlah pembeli Pimento terbesar, yaitu sebanyak dua supermarket. Total responden keseluruhan yang diambil dari dua supermarket tersebut sebanyak 31 responden.

Metode analisis yang digunakan adalah analisis deskriptif dan uji - $\mathrm{t}$ tidak berpasangan karena sesuai dengan tujuan yang ingin dicapai yaitu untuk mengetahui apakah buah Pimento ini dapat bersaing dan diterima di pasar serta faktor-faktor yang menjadi pertimbangan konsumen dalam membeli dan mengkonsumsi buah Pimento. Uji $-\mathrm{t}$ tidak berpasangan digunakan untuk mengetahui apakah buah Pimento ini dapat bersaing atau tidak di pasaran dengan cara mencari perbandingan tingkat persentase penjualan antara buah Pimento dengan persentase penjualan buah Paprika. Uji - t tidak berpasangan banyak dipakai karena mudah perhitungannya serta mempunyai satu nilai pembanding. Untuk mencari atau menganalisis apakah Pimento dapat diterima di pasar atau tidak, maka data yang diperoleh dianalisis secara deskriptif. Indikator penerimaan konsumen adalah tingkat kepuasan akan Pimento. Tingkat kepuasan Pimento oleh konsumen didapatkan dengan pemberian skor atau penilaian pada masing-masing parameter. Setelah dilakukan analisis secara deskriptif, selanjutnya dilakukan analisis secara statistik dengan uji Mann Whitney. Uji Mann Whitney ini dilakukan untuk menguji signifikasi hipotesis dua sampel independen bila datanya berbentuk ordinal (Sugiyono, 2007). Uji ini juga dilakukan bila data sebelumnya yang berbentuk data parametrik dan telah diuji normalitasnya menghasilkan data tidak normal. Uji Mann Whitney dilakukan dengan menggunakan program Minitab 14.

\section{Hasil Dan Pembahasan}

\section{Jenis Kelamin Responden}

Berdasarkan data yang diambil selama penelitian, dapat diketahui bahwa responden terbanyak adalah perempuan yang berjumlah 26 responden atau 83,87\% disusul responden laki-laki sebanyak 5 responden atau $16,13 \%$.

Tabel 1. Karakteristik Responden berdasarkan Jenis Kelamin

\begin{tabular}{cccc}
\hline No & Jenis Kelamin & Jumlah responden (orang) & Persentase (\%) \\
\hline 1 & Laki-laki & 5 & 16,13 \\
2 & Perempuan & 26 & 83,87 \\
\hline & Jumlah & 31 & 100 \\
\hline
\end{tabular}


Banyaknya responden perempuan yang berbelanja di kedua supermarket tersebut disebabkan karena wanita memiliki kewajiban dalam mengambil keputusan untuk berbelanja dalam memenuhi kebutuhan rumah tangga. Sebagian besar wanita yang berbelanja adalah ibu rumah tangga karena mereka punya banyak waktu luang untuk berbelanja dan berpergian serta sebagai ibu rumah tangga mereka punya kewajiban yang sangat penting dalam memenuhi kebutuhan rumah tangga. Selain itu karakter dari sebagian wanita yang memiliki hobi berbelanja baik makanan atau kebutuhan lainnya, ikut mempengaruhi banyaknya responden perempuan yang berbelanja di kedua supermarket tersebut.

\section{Asal Kewarganegaraan Responden}

Berdasarkan data yang diambil selama penelitian, dapat diketahui bahwa responden terbanyak adalah warga negara asing sebesar 24 responden atau 77,42\%, sedangkan warga negara Indonesia hanya 7 responden atau $22,58 \%$. Warga negara asing yang berkunjung ke supermarket-supermarket tersebut mayoritas berasal dari Australia sebanyak 14 responden, Eropa (Belanda, Jerman, Spanyol, Prancis) sebanyak 5 responden dan Asia Timur (Jepang, Korea Selatan, Taiwan) sebanyak 5 responden. Sedangkan warga negara Indonesia yang berkunjung ke supermarket tersebut mayoritas berdomisili di Bali sebanyak 6 responden dan luar Bali (Jakarta) sebanyak 1 responden.

Tabel 2. Karakteristik Responden berdasarkan Asal Kewarganegaraan

\begin{tabular}{cccc}
\hline No & Kewarganegaraan & Jumlah responden (orang) & Persentase (\%) \\
\hline 1 & WNA & 24 & 77,42 \\
2 & WNI & 7 & 22,58 \\
\hline & Jumlah & 31 & 100 \\
\hline
\end{tabular}

Banyaknya warga negara asing atau ekspatriat yang berbelanja di kedua supermarket tersebut disebabkan karena buah Pimento ini sudah cukup dikenal oleh mereka terutama di negara asal. Sedangkan bagi warga negara Indonesia sendiri, buah Pimento ini tergolong produk yang masih baru dan hanya dikenal oleh beberapa kalangan saja. Sebagian dari mereka mengenal produk ini karena status sosial dan lingkungan pergaulan yang sering berhubungan dengan masyarakat kalangan atas atau kaum ekspatriat. Bahkan beberapa dari responden wanita tersebut ada yang menikah dengan para ekspatriat sehingga dari pernikahan tersebut membuat mereka memiliki status sosial dan pergaulan yang lebih luas lagi terutama dengan kaum ekspatriat.

\section{Pendidikan Responden}

Berdasarkan data yang diambil selama penelitian, dapat diketahui bahwa responden yang memiliki tingkat pendidikan sarjana (S1) atau setara sarjana (D3) sebanyak 24 responden atau sekitar 77,41\%. Sedangkan yang berpendidikan SMA sebanyak 7 responden atau $22,59 \%$.

Tabel 3. Karakteristik Responden berdasarkan Tingkat Pendidikan

\begin{tabular}{cccc}
\hline No & Tingkat Pendidikan & Jumlah Responden (orang) & Persentase (\%) \\
\hline 1 & Sarjana/Diploma (S1/D3) & 24 & 77,41 \\
2 & SMA & 7 & 22,59 \\
\hline & Jumlah & 31 & 100 \\
\hline
\end{tabular}

Banyaknya responden yang memiliki tingkat pendidikan S1 atau D3 disebabkan karena semakin tingginya tingkat pendidikan mempengaruhi pola berpikir responden dalam menilai suatu produk dan dapat merubah pandangan responden terhadap produk tersebut. Untuk responden yang berpendidikan SMA, pengetahuan tentang buah Pimento ini didapat 
karena status sosial dan pergaulan dengan kaum ekspatriat khususnya bagi para warga negara Indonesia yang kebetulan bersuamikan warga negara asing.

\section{Pekerjaan Responden}

Berdasarkan data yang diambil selama penelitian, dapat diketahui bahwa responden terbanyak adalah ibu rumah tangga sebanyak 12 responden atau 38,70\%. Selanjutnya adalah wiraswasta sebanyak 9 responden atau $29,05 \%$, karyawan swasta sebanyak 7 responden atau $22,58 \%$ dan mahasiswa sebanyak 3 responden atau 9,67\%.

Tabel 4. Karakteristik Responden berdasarkan Jenis Pekerjaan

\begin{tabular}{cccc}
\hline No & Jenis Pekerjaan & Jumlah Responden (orang) & Persentase (\%) \\
\hline 1 & Karyawan Swasta & 7 & 22,58 \\
2 & Mahasiswa & 3 & 9,67 \\
3 & Wiraswasta & 9 & 29,05 \\
4 & Ibu Rumah Tangga & 12 & 38,70 \\
\hline & Jumlah & 31 & 100 \\
\hline
\end{tabular}

Banyaknya ibu rumah tangga yang berbelanja di kedua supermarket tersebut karena ibu rumah tangga lebih banyak punya waktu luang untuk berbelanja atau berpergian dibandingkan dengan karyawan atau wiraswasta yang memiliki sedikit waktu luang untuk berbelanja karena kesibukan pekerjaan mereka.

\section{Penghasilan Responden}

Berdasarkan data yang diambil selama penelitian, dapat diketahui bahwa sebanyak 15 responden atau sekitar 48,38 \% tidak memiliki penghasilan. Mereka ini umumnya terdiri dari ibu rumah tangga dan mahasiswa. Sedangkan sisanya yaitu berjumlah sebanyak 16 responden atau sekitar 51,62 \% yang terdiri dari wiraswasta dan karyawan swasta memiliki penghasilan sekitar 11-20 juta atau lebih.

Tabel 5. Karakteristik Responden berdasarkan Jumlah Penghasilan

\begin{tabular}{cccc}
\hline No & Jumlah Penghasilan & Jumlah Responden (orang) & Persentase (\%) \\
\hline 1 & Tidak ada & 15 & 48,38 \\
2 & $\geq 11-20$ juta & 16 & 51,62 \\
\hline & Jumlah & 31 & 100 \\
\hline
\end{tabular}

Banyaknya responden berpenghasilan diatas 11-20 juta atau lebih yang berbelanja di kedua supermarket tersebut disebabkan karena buah Pimento ini sudah banyak dikenal oleh kalangan menengah atas dan kaum ekspatriat yang sebagian besar berpenghasilan di atas 10 juta. Dengan penghasilan sebesar ini mereka mampu membeli produk dengan harga yang cukup mahal bahkan yang paling mahal sekalipun. Sedangkan bagi ibu rumah tangga dan mahasiswa yang tidak memiliki penghasilan, sumber keuangan mereka didapat dari suami bagi ibu rumah tangga dan dari orang tua bagi mahasiswa.

\section{Kemampuan bersaing di pasaran}

Kemampuan bersaing dalam hal ini adalah bagaimana kemampuan buah Pimento untuk bersaing di pasaran dibandingkan dengan buah Paprika. Hal ini dapat diketahui dari indikator penjualan dan pengulangan pembelian buah Pimento di pasaran dibandingkan dengan buah Paprika. Parameter dari indikator penjualan antara lain rata-rata harga dan ratarata jumlah pembelian buah Pimento dibandingkan buah Paprika. Sedangkan parameter dari pengulangan pembelian yaitu rata-rata frekwensi pembelian buah Pimento dibandingkan buah Paprika oleh responden. 


\section{Perbandingan rata-rata jumlah pembelian (kg/org/bln)}

Analisis statistik untuk perbandingan rata-rata jumlah pembelian (kg/org/bln) dilakukan dengan analisis uji $\mathrm{F}$ dan uji t.

Tabel 6. Hasil Analisis Statistik Perbandingan Rata-rata Jumlah Pembelian (kg/org/bln)

\begin{tabular}{|c|c|c|c|c|c|c|c|c|}
\hline \multirow[t]{2}{*}{ Parameter } & \multicolumn{2}{|c|}{$\begin{array}{l}\text { Rata-rata } \\
\text { jumlah } \\
\text { pembelian } \\
\text { per kg }\end{array}$} & \multicolumn{2}{|c|}{ Uji F } & \multicolumn{3}{|c|}{ Uji t } & \multirow[t]{2}{*}{ Kesimpulan } \\
\hline & $\begin{array}{l}\text { Pim } \\
\text { ento }\end{array}$ & $\begin{array}{l}\text { Pap } \\
\text { rika }\end{array}$ & F hitung & F tabel & t hitung & $\begin{array}{c}\mathrm{t} \\
\text { tabel }\end{array}$ & $\begin{array}{c}\text { Pelua } \\
\text { ng t } \\
\text { (p) }\end{array}$ & \\
\hline $\begin{array}{l}\text { Perbandingan } \\
\text { rata-rata jumlah } \\
\text { pembelian per } \\
\text { kg }\end{array}$ & 0,63 & 2,29 & 5,28 & 1,84 & 8,11 & 2,01 & 0,00 & $\begin{array}{l}\text { berbeda sangat } \\
\text { nyata }\end{array}$ \\
\hline
\end{tabular}

Berdasarkan hasil uji $\mathrm{F}$ dan hasil uji t dapat diketahui bahwa nilai $\mathrm{F}$ hitung $>$ nilai $\mathrm{F}$ tabel yang berarti KT A $\neq$ KT B (kedua varian dianggap heterogen). Setelah dianalisis dengan uji $\mathrm{t}$ dapat diketahui bahwa $\mathrm{t}$ hitung $(8,11)>\mathrm{t}$ tabel $(2,01)$ atau peluang $\mathrm{t}(\mathrm{p})$ sebesar $0,00 \leq 0,01$ yang berarti terdapat perbedaan yang sangat nyata antara jumlah pembelian Pimento dan jumlah pembelian Paprika. Hal ini juga dapat dilihat dari besarnya perbandingan rata-rata jumlah pembelian Pimento sebesar $0,63 \mathrm{~kg} / \mathrm{org} / \mathrm{bln}$ dan rata-rata jumlah pembelian Paprika sebesar 2,29 kg/org/bln yang berarti jumlah pembelian Paprika oleh responden masih lebih banyak daripada jumlah pembelian Pimento. Dari segi jumlah pembelian, dapat diketahui bahwa Pimento belum bisa bersaing dengan Paprika. Hal ini disebabkan antara lain responden belum banyak yang mengenal Pimento serta harga Pimento yang cukup mahal.

\section{Perbandingan rata-rata harga per kg}

Analisis statistik untuk perbandingan rata-rata harga per kg dilakukan dengan analisis uji $\mathrm{F}$ dan uji t.

Tabel 7. Hasil Analisis Statistik Perbandingan Rata-rata Harga Per Kg

\begin{tabular}{|c|c|c|c|c|c|c|c|c|}
\hline \multirow[t]{2}{*}{ Parameter } & Rata-rata & ga per kg & \multicolumn{2}{|c|}{ Uji F } & \multicolumn{3}{|c|}{ Uji t } & \multirow{2}{*}{$\underset{\mathrm{n}}{\text { Kesimpula }}$} \\
\hline & Pimento & Paprika & $\begin{array}{c}\mathrm{F} \\
\text { hitung }\end{array}$ & $\begin{array}{c}\mathrm{F} \\
\text { tabel }\end{array}$ & $\begin{array}{c}\mathrm{t} \\
\text { hitung }\end{array}$ & $\begin{array}{c}\mathrm{t} \\
\text { tabel }\end{array}$ & $\begin{array}{l}\text { Pelu } \\
\text { ang } \\
t(p)\end{array}$ & \\
\hline $\begin{array}{l}\text { Perbandinga } \\
\mathrm{n} \text { rata-rata } \\
\text { harga per } \mathrm{kg}\end{array}$ & 144935,48 & 35854,83 & 0,00 & 0,54 & 113,95 & 2,04 & 0,00 & $\begin{array}{l}\text { berbeda } \\
\text { sangat } \\
\text { nyata }\end{array}$ \\
\hline
\end{tabular}

Berdasarkan hasil uji $\mathrm{F}$ dan uji $\mathrm{t}$ dapat diketahui bahwa nilai $\mathrm{F}$ hitung $<\mathrm{F}$ tabel yang berarti KT A = KT B (kedua varian dianggap homogen). Setelah dianalisis dengan uji $\mathrm{F}$ dan uji $t$, dapat diketahui bahwa $t$ hitung $(113,95)>t$ tabel $(2,04)$ atau peluang $t(p) \leq 0,01$ yang berarti terdapat perbedaan yang sangat nyata antara harga Pimento dan harga Paprika. Hal ini juga dapat dilihat dari besarnya rata-rata harga Pimento sebesar Rp 144.935,48,- per kg dan rata-rata harga Paprika sebesar Rp 35.854,83,- per kg yang berarti harga Pimento per kg nya masih lebih mahal daripada harga Paprika per kg nya. Dari perbandingan rata-rata harga tersebut dapat diketahui bahwa harga Pimento belum bisa bersaing dengan Paprika. Responden sendiri juga cenderung lebih suka membeli buah Paprika yang lebih murah daripada buah Pimento karena harga Paprika sendiri di pasaran berkisar antara Rp 25.000,/kg hingga Rp 50.000,-/kg. Sedangkan harga Pimento mencapai Rp 145.000,-/kg. Harga Pimento per kg yang lebih mahal daripada Paprika mengindikasikan bahwa Pimento untuk 
saat ini hanya dinikmati oleh kalangan atas maupun para ekspatriat dan belum menjangkau kalangan menengah ke bawah.

\section{Perbandingan rata-rata frekuensi pembelian per bulan}

Analisis statistik untuk perbandingan rata-rata frekuensi pembelian per bulan dilakukan dengan analisis uji $\mathrm{F}$ dan uji t.

Tabel 8. Hasil Analisis Statistik Perbandingan Rata-rata Frekuensi Pembelian Per Bulan

\begin{tabular}{|c|c|c|c|c|c|c|c|c|}
\hline \multirow[t]{2}{*}{ Parameter } & \multicolumn{2}{|c|}{$\begin{array}{l}\text { Rata-rata frekuensi } \\
\text { pembelian per bulan }\end{array}$} & \multicolumn{2}{|c|}{ Uji F } & \multicolumn{3}{|c|}{ Uji t } & \multirow[t]{2}{*}{$\underset{n}{\text { Kesimpula }}$} \\
\hline & Pimento & Paprika & $\begin{array}{c}\mathrm{F} \\
\text { hitung }\end{array}$ & $\begin{array}{c}\mathrm{F} \\
\text { tabel }\end{array}$ & $\begin{array}{c}\mathrm{t} \\
\text { hitung }\end{array}$ & $\begin{array}{c}\mathrm{t} \\
\text { tabel }\end{array}$ & $\begin{array}{c}\text { Pelua } \\
\text { ng t } \\
\text { (p) }\end{array}$ & \\
\hline $\begin{array}{l}\text { Perbandingan } \\
\text { frekuensi } \\
\text { pembelian } \\
\text { per bulan }\end{array}$ & 3,19 & 9,74 & 6,90 & 1,84 & 7,90 & 2,02 & 0,00 & $\begin{array}{l}\text { berbeda } \\
\text { sangat } \\
\text { nyata }\end{array}$ \\
\hline
\end{tabular}

Berdasarkan hasil uji $\mathrm{F}$ dan uji $\mathrm{t}$ dapat diketahui bahwa nilai $\mathrm{F}$ hitung $>\mathrm{F}$ tabel yang berarti KT A $\neq$ KT B (kedua varian dianggap heterogen). Setelah dianalisis dengan uji F dan uji $\mathrm{t}$ dapat diketahui bahwa $\mathrm{t}$ hitung $(7,90)>\mathrm{t}$ tabel $(2,02)$ atau peluang $\mathrm{t}(\mathrm{p}) \leq 0,01$ yang berarti terdapat perbedaan yang sangat nyata antara frekuensi pembelian Pimento dan frekuensi pembelian Paprika. Hal ini juga dapat dilihat dari besarnya rata-rata frekuensi pembelian Pimento sebesar 3,19 kali per bulan dan rata-rata frekuensi pembelian Paprika sebesar 9,74 kali per bulan. Dari hasil perbandingan rata-rata frekuensi pembelian Pimento dan Paprika dapat diambil kesimpulan bahwa responden lebih sering membeli Paprika daripada Pimento yang berarti dari segi frekuensi pembelian, Pimento belum bisa bersaing dengan Paprika. Salah satu alasan responden lebih sering membeli Paprika dari pada Pimento antara lain harga Pimento yang mahal dari pada Paprika sehingga responden yang akan membeli Pimento harus menyesuaikan dengan kondisi keuangan dan kebutuhan sehari-hari responden.

\section{Keputusan konsumen dalam melakukan pembelian}

Keputusan konsumen adalah keputusan dari masing-masing responden dalam membeli buah Pimento tersebut dibandingkan dengan buah Paprika. Hal ini dapat diketahui dari karakteristik buah Pimento, fluktuasi harga, manfaat buah Pimento, lama daya simpan, serta pengemasan buah Pimento yang menjadi alasan responden untuk membeli buah Pimento dibandingkan dengan buah Paprika.

Parameter dari indikator karakteristik buah antara lain ukuran, rasa, warna, tekstur, aroma, bentuk buah Pimento dibandingkan buah Paprika. Parameter dari indikator harga jual adalah bagaimana fluktuasi harga Pimento dibandingkan Paprika. Parameter dari indikator manfaat antara lain manfaat Pimento untuk kesehatan, sebagai hidangan utama, dan sebagai pelengkap hidangan utama. Parameter dari indikator pengemasan yaitu cara pengemasan Pimento dibandingkan Paprika. Sedangkan parameter dari indikator daya simpan yaitu lama penyimpanan Pimento dibandingkan Paprika.

\section{Analisis deskriptif variabel keputusan konsumen dalam melakukan pembelian}

Analisis deskriptif variabel keputusan konsumen dalam melakukan pembelian dapat dilihat dari hasil pencapaian skor masing-masing parameter yang disajikan pada tabel di bawah. 
Tabel 9. Hasil Pencapaian Skor Variabel Keputusan Konsumen Melakukan Pembelian

\begin{tabular}{|c|c|c|c|c|c|c|}
\hline \multirow[t]{2}{*}{ Parameter } & \multicolumn{3}{|c|}{ Pimento } & \multicolumn{3}{|c|}{ Paprika } \\
\hline & $\%$ & Angka & Keterangan & $\%$ & Angka & Keterangan \\
\hline Ukuran & 73 & 3,65 & Besar & 90 & 4,48 & Sangat Besar \\
\hline Rasa & 85 & 4,26 & Sangat Manis & 72 & 3,58 & Manis \\
\hline Warna & 86 & 4,29 & Sangat Menarik & 70 & 3,48 & Menarik \\
\hline Bentuk & 89 & 4,45 & Sangat Menarik & 69 & 3,45 & Menarik \\
\hline Tekstur & 85 & 4,23 & Sangat Halus & 68 & 3,42 & Halus \\
\hline Aroma & 86 & 4,29 & $\begin{array}{l}\text { Sangat Menggugah } \\
\text { Selera }\end{array}$ & 66 & 3,32 & $\begin{array}{l}\text { Cukup } \\
\text { Menggugah } \\
\text { Selera }\end{array}$ \\
\hline Fluktuasi Harga & 83 & 4,13 & Sangat Stabil & 63 & 3,16 & Cukup Stabil \\
\hline $\begin{array}{l}\text { Manfaat untuk } \\
\text { kesehatan }\end{array}$ & 85 & 4,23 & Sangat Bermanfaat & 64 & 3,19 & $\begin{array}{l}\text { Cukup } \\
\text { Bermanfaat }\end{array}$ \\
\hline $\begin{array}{l}\text { Manfaat sebagai } \\
\text { hidangan utama }\end{array}$ & 86 & 4,32 & Sangat Bermanfaat & 66 & 3,29 & $\begin{array}{l}\text { Cukup } \\
\text { Bermanfaat }\end{array}$ \\
\hline $\begin{array}{l}\text { Manfaat sebagai } \\
\text { hidangan pelengkap }\end{array}$ & 67 & 3,35 & Cukup Bermanfaat & 87 & 4,35 & $\begin{array}{l}\text { Sangat } \\
\text { Bermanfaat }\end{array}$ \\
\hline Cara Pengemasan & 84 & 4,19 & Sangat Bagus & 65 & 3,23 & Cukup Bagus \\
\hline Lama Penyimpanan & 85 & 4,23 & Sangat Tahan Lama & 68 & 3,39 & Tahan Lama \\
\hline
\end{tabular}

\section{Analisis statistik variabel keputusan konsumen dalam melakukan pembelian}

Analisis statistik untuk variabel keputusan konsumen untuk membeli dilakukan dengan uji Mann Whitney karena berbentuk data ordinal.

Tabel 10. Hasil Analisis Statistik Variabel Keputusan Konsumen Melakukan Pembelian

\begin{tabular}{|c|c|c|c|c|c|c|}
\hline \multirow[t]{2}{*}{ Parameter } & \multicolumn{2}{|c|}{ Nilai Median } & \multicolumn{2}{|c|}{ Nilai Rata-rata } & \multirow[t]{2}{*}{ Peluang } & \multirow{2}{*}{$\underset{\mathbf{n}}{\text { Kesimpula }}$} \\
\hline & Pimento & Paprika & Pimento & Paprika & & \\
\hline Ukuran & 4,00 & 5,00 & 3,65 & 4,48 & 0,00 & $\begin{array}{c}\text { Berbeda } \\
\text { Sangat } \\
\text { Nyata }\end{array}$ \\
\hline Rasa & 5,00 & 4,00 & 4,26 & 3,58 & 0,01 & $\begin{array}{c}\text { Berbeda } \\
\text { Sangat } \\
\text { Nyata }\end{array}$ \\
\hline Warna & 4,00 & 4,00 & 4,29 & 3,48 & 0,00 & $\begin{array}{c}\text { Berbeda } \\
\text { Sangat } \\
\text { Nyata }\end{array}$ \\
\hline Bentuk & 5,00 & 4,00 & 4,45 & 3,45 & 0,00 & $\begin{array}{c}\text { Berbeda } \\
\text { Sangat } \\
\text { Nyata }\end{array}$ \\
\hline Tekstur & 5,00 & 4,00 & 4,23 & 3,42 & 0,01 & $\begin{array}{c}\text { Berbeda } \\
\text { Sangat } \\
\text { Nyata }\end{array}$ \\
\hline Aroma & 4,00 & 3,00 & 4,29 & 3,32 & 0,00 & $\begin{array}{c}\text { Berbeda } \\
\text { Sangat } \\
\text { Nyata }\end{array}$ \\
\hline Fluktuasi harga & 4,00 & 3,00 & 4,13 & 3,16 & 0,00 & $\begin{array}{c}\text { Berbeda } \\
\text { Sangat } \\
\text { Nyata }\end{array}$ \\
\hline
\end{tabular}


Tabel 10. Lanjutan

\begin{tabular}{|c|c|c|c|c|c|c|}
\hline \multirow[t]{2}{*}{ Parameter } & \multicolumn{2}{|c|}{ Nilai Median } & \multicolumn{2}{|c|}{ Nilai Rata-rata } & \multirow[t]{2}{*}{ Peluang } & \multirow{2}{*}{$\underset{n}{\text { Kesimpula }}$} \\
\hline & Pimento & Paprika & Pimento & Paprika & & \\
\hline $\begin{array}{l}\text { Manfaat untuk } \\
\text { kesehatan }\end{array}$ & 5,00 & 3,00 & 4,23 & 3,19 & 0,00 & $\begin{array}{l}\text { Berbeda } \\
\text { Sangat } \\
\text { Nyata }\end{array}$ \\
\hline $\begin{array}{l}\text { Manfaat untuk } \\
\text { hidangan utama }\end{array}$ & 5,00 & 3,00 & 4,32 & 3,29 & 0,00 & $\begin{array}{c}\text { Berbeda } \\
\text { Sangat } \\
\text { Nyata }\end{array}$ \\
\hline $\begin{array}{l}\text { Manfaat untuk } \\
\text { hidangan pelengkap }\end{array}$ & 4,00 & 5,00 & 3,35 & 4,35 & 0,00 & $\begin{array}{c}\text { Berbeda } \\
\text { Sangat } \\
\text { Nyata }\end{array}$ \\
\hline Cara pengemasan & 4,00 & 3,00 & 4,19 & 3,23 & 0,00 & $\begin{array}{c}\text { Berbeda } \\
\text { Sangat } \\
\text { Nyata }\end{array}$ \\
\hline Lama penyimpanan & 5,00 & 4,00 & 4,23 & 3,39 & 0,00 & $\begin{array}{c}\text { Berbeda } \\
\text { Sangat } \\
\text { Nyata }\end{array}$ \\
\hline
\end{tabular}

\section{Stok Penjualan}

Stok penjualan menunjukkan bagaimana ketersediaan stok buah Pimento selama dijual di supermarket. Hal ini dapat diketahui dari ketersediaan dan kemudahan dalam memperoleh buah Pimento di supermarket. Parameter dari ketersediaan buah adalah apakah buah Pimento selalu tersedia di supermarket saat dibutuhkan. Sedangkan parameter dari kemudahan memperoleh adalah apakah buah Pimento tersebut mudah diperoleh di supermarket atau tidak.

\section{Analisis deskriptif variabel stok penjualan}

Analisis deskriptif variabel stok penjualan dapat dilihat dari hasil pencapaian skor masing-masing parameter yang disajikan pada tabel di bawah

Tabel 11. Hasil Pencapaian Skor Variabel Stok Penjualan

\begin{tabular}{ccccccc}
\hline Parameter & \multicolumn{4}{c}{ Pimento } & \multicolumn{3}{c}{ Paprika } \\
\cline { 2 - 7 } & $\%$ & Angka & Keterangan & $\%$ & Angka & Keterangan \\
\hline $\begin{array}{c}\text { Ketersediaan di } \\
\text { supermarket }\end{array}$ & 70 & 3,52 & Tersedia & 88 & 4,39 & $\begin{array}{c}\text { Sangat } \\
\text { Tersedia } \\
\text { Kemudahan memperoleh }\end{array}$ \\
72 & 3,58 & Mudah Diperoleh & 90 & 4,48 & $\begin{array}{c}\text { Sangat } \\
\text { Mudah } \\
\text { Diperoleh }\end{array}$ \\
\hline
\end{tabular}

\section{Analisis statistik variabel stok penjualan}

Analisis statistik untuk variabel stok penjualan dilakukan dengan uji Mann Whitney karena berbentuk data ordinal. 
Tabel 12. Hasil Analisis Statistik Variabel Stok Penjualan

\begin{tabular}{|c|c|c|c|c|c|c|c|}
\hline \multirow[t]{2}{*}{ Parameter } & & \multicolumn{2}{|c|}{ Nilai Median } & \multicolumn{2}{|c|}{ Nilai Rata-rata } & \multirow[t]{2}{*}{ Peluang } & \multirow{2}{*}{$\begin{array}{c}\text { Kesimp } \\
\text { ulan }\end{array}$} \\
\hline & & Pimento & Paprika & Pimento & Paprika & & \\
\hline $\begin{array}{l}\text { Ketersediaan } \\
\text { supermarket }\end{array}$ & $\mathrm{di}$ & 4,00 & 5,00 & 3,52 & 4,39 & 0,00 & $\begin{array}{c}\text { Berbeda } \\
\text { Sangat } \\
\text { Nyata }\end{array}$ \\
\hline $\begin{array}{l}\text { Kemudahan } \\
\text { memperoleh }\end{array}$ & & 4,00 & 5,00 & 3,58 & 4,48 & 0,00 & $\begin{array}{c}\text { Berbeda } \\
\text { Sangat } \\
\text { Nyata }\end{array}$ \\
\hline
\end{tabular}

\section{Parameter yang menjadi pertimbangan responden dalam membeli dan mengkonsumsi Pimento}

Dalam penelitian mengenai Uji Pasar Buah Pimento, ada beberapa parameter yang menjadi pertimbangan konsumen dalam membeli dan mngkonsumsi buah Pimento. Parameter-parameter tersebut terdapat dalam variabel keputusan konsumen dalam melakukan pembelian. Dari variabel tersebut dibagi menjadi lima indikator yang masing-masing terdiri dari beberapa parameter yaitu karakteristik (ukuran, rasa, warna, tekstur, aroma, bentuk), harga jual (fluktuasi harga), manfaat (kesehatan, hidangan utama, hidangan pelengkap), pengemasan (cara pengemasan), dan daya simpan (lama penyimpanan).

Dari beberapa parameter tersebut selanjutnya disusun berdasarkan rata-rata responden yang menjawab dengan nilai rata-rata terbesar. Dari parameter-parameter tersebut diambil lima parameter yang memiliki nilai rata-rata terbesar yang menjadi pertimbangan dalam membeli dan mengkonsumsi buah Pimento.

Tabel 13. Parameter yang menjadi pertimbangan responden dalam membeli dan mengkonsumsi Pimento

\begin{tabular}{clcl}
\hline No & \multicolumn{1}{c}{ Parameter } & Rata-rata & \multicolumn{1}{c}{ Keterangan } \\
\hline 1 & Bentuk & 4,45 & Sangat Menarik \\
2 & Manfaat sebagai hidangan utama & 4,32 & Sangat Bermanfaat \\
3 & Aroma & 4,29 & Sangat Menggugah Selera \\
4 & Warna & 4,29 & Sangat Menarik \\
5 & Rasa & 4,26 & Sangat Manis \\
6 & Manfaat untuk kesehatan & 4,23 & Sangat Bermanfaat \\
7 & Tekstur & 4,23 & Sangat Halus \\
8 & Lama Penyimpanan & 4,23 & Sangat Tahan Lama \\
9 & Cara Pengemasan & 4,19 & Sangat Bagus \\
10 & Fluktuasi Harga & 4,13 & Sangat Stabil \\
11 & Ukuran & 3,65 & Besar \\
12 & Manfaat sebagai hidangan pelengkap & 3,35 & Cukup Bermanfaat \\
\hline
\end{tabular}

Berdasarkan tabel di atas dapat diketahui bahwa terdapat lima parameter utama yang memiliki nilai rata-rata terbesar dan menjadi pertimbangan responden dalam membeli dan mengkonsumsi buah Pimento. Lima parameter tersebut adalah bentuk $(4,45)$, manfaat sebagai hidangan utama $(4,32)$, aroma $(4,29)$, manfaat untuk kesehatan $(4,29)$, dan rasa $(4,26)$.

Alasan bentuk dipilih sebagai alasan terbanyak karena Pimento mempunyai bentuk yang sangat menarik mirip dengan Cabai sehingga membuat orang berminat untuk membeli dan mencoba buah Pimento tersebut. Parameter bentuk memiliki nilai rata-rata terbesar dari parameter lainnya yaitu 4,45. Pemilihan parameter bentuk sebagai alasan terbanyak juga 
didukung dengan manfaat dari Pimento tersebut yang sering dijadikan sebagai salah satu hidangan utama antara lain disajikan sebagai sup atau salad. Selain bentuk yang sangat menarik dan manfaat sebagai makanan utama, ketertarikan konsumen untuk membeli Pimento juga didukung dengan rasa yang sangat manis, warna yang sangat menarik, dan aroma Pimento yang menggugah selera sehingga membuat konsumen berminat untuk membeli dan mencoba buah Pimento.

Namun untuk saat ini buah Pimento hanya bisa dinikmati oleh kalangan terbatas saja yaitu masyarakat kalangan menengah atas dan kaum ekspatriat karena harga buah Pimento yang masih mahal yaitu Rp 145.000 per $\mathrm{kg}$ atau Rp 29.000 per pack sehingga belum bisa dinikmati seluruh lapisan masyarakat terutama masyarakat menengah ke bawah. Bahkan buah Pimento ini belum dijual secara luas di pasaran sehingga untuk membeli buah Pimento konsumen harus mencari di tempat-tempat tertentu yang khusus menjual buah Pimento. Sehingga untuk ke depannya diharapkan buah Pimento ini dapat dikenal dan dinikmati secara luas oleh seluruh kalangan masyarakat dan tidak terbatas pada kalangan tertentu saja.

\section{Kesimpulan Dan Saran}

\section{Kesimpulan}

Berdasarkan hasil analisis dan pembahasan, maka dapat disimpulkan beberapa hal sebagai berikut:

1. Berdasarkan variabel kemampuan bersaing di pasaran, untuk saat ini buah Pimento belum bisa bersaing dengan buah Paprika. Hal ini dapat diketahui dari rata-rata harga Pimento sebesar Rp 144935,48 per kg yang lebih mahal dari pada rata-rata harga Paprika yaitu sebesar Rp 35854,83,- per kg, rata-rata jumlah pembelian Paprika sebesar 2,29 $\mathrm{kg} / \mathrm{org} / \mathrm{bln}$ yang lebih besar dari pada rata-rata jumlah pembelian Pimento sebesar 0,63 $\mathrm{kg} / \mathrm{org} / \mathrm{bln}$ serta rata-rata frekuensi pembelian Paprika oleh responden sebesar 9,74 kali per bulan yang lebih besar dari pada rata-rata frekuensi pembelian Pimento oleh responden sebesar 3,19 kali per bulan.

2. Pada saat ini buah Pimento diterima secara terbatas pada kalangan menengah atas dan kaum ekspatriat. Lokasi penjualannya saat ini hanya berada di beberapa tempat tertentu saja antara lain di Freshtiv, Canggu Deli, Papaya's, Bintang, dan Carefour yang hampir semuanya berada di daerah Kuta. Berbeda dengan Paprika yang mudah diperoleh di hampir seluruh supermarket termasuk supermarket yang ada di Denpasar seperti Hardy's dan Tiara Dewata.

3. Parameter utama yang menjadi pertimbangan konsumen untuk membeli dan mengkonsumsi Pimento adalah bentuk yang sangat menarik, manfaat sebagai hidangan utama, aroma yang menggugah selera, warna yang sangat menarik, dan rasa yang sangat manis.

\section{Saran} berikut:

Berdasarkan hasil penelitian di atas maka dapat disarankan beberapa hal sebagai

1. Buah Pimento perlu dipromosikan lebih luas dan tempat pemasaran buah Pimento perlu diperbanyak lagi tidak hanya terbatas di lokasi-lokasi tertentu saja bahkan jika perlu dipasarkan di supermarket yang ada di seluruh wilayah Indonesia agar buah Pimento dapat lebih dikenal oleh masyarakat luas. 
2. Segmentasi pasar dari buah Pimento diharapkan bisa diperluas lagi dan tidak hanya menjangkau masyarakat kalangan atas dan warga negara asing tetapi juga menjangkau masyarakat lapisan bawah.

3. Untuk kedepannya diharapkan harga buah Pimento bisa lebih murah lagi di tingkat penjual agar harganya dapat terjangkau oleh masyarakat luas sehingga Pimento ini dapat dinikmati oleh seluruh lapisan masyarakat dan tidak hanya dinikmati oleh kalangan tertentu saja.

4. Perlu adanya penelitian lanjutan mengenai tanaman dan buah Pimento itu sendiri baik dari segi budidaya maupun dari segi sosial ekonomi agar masyarakat dapat mengetahui dan memperoleh manfaat dari Pimento itu sendiri.

\section{Daftar Pustaka}

Antara, M. 2009. Pertanian, Bangkit atau Bangkrut. Arti Foundation. Denpasar.

Cooper, D.R. dan Schindler, P.S. 2006. Metode Riset Bisnis. PT. Media Global Edukasi. Jakarta.

Gunadi, N. 2006. Budidaya Tanaman Paprika (Capsicum annum var grossum) di Dalam Rumah Plastik. Balai Penelitian Tanaman Sayuran. Bandung.

Kotler, P dan Amstrong, G. 2008. Prinsip-prinsip Pemasaran. Penerbit Erlangga. Jakarta.

Lempsey, F.D. 2004. Cultivation Capsicum Sp. on Tropical Areal. University of Wageneingen. Wageneingen.

Riana. 2015. Potensi Budidaya Pimento Masih Terbuka Lebar. www.jitunews.com.

Supartha, N. 2005. Pendekatan Holistik Membangun Agribisnis. CV. Bali Media Adhikarsa. Denpasar.

Sugiyono. 2007. Metode Penelitian Bisnis. CV Alfabeta. Bandung.

Widhiarso, D., Kim, I.T., Vart, R.V.D., dan Edwin, V.D. 2011. Review of Paprika Pimento in Indonesia. Doughen Seed, Co.Ltd Publication. Den Bosch. 